\title{
Gestão de unidade básica de saúde em municípios de pequeno porte: instrumentos utilizados, facilidades e dificuldades relacionadas
}

\section{Gestión de la unidad básica de salud en pequeñas ciudades: instrumentos utilizados y facilidades y dificultades relacionadas}

\section{Management of the Basic Health Unit in Small Municipalities: Instruments, Facilities and Related Difficulties}

Fecha de recepción: 02-01-14 Fecha de aceptación: 02-03-14 Disponible en línea: 01-07-14 doi: 10.11144/Javeriana.rgyps13-27.gubs

Cómo citar este artículo:

Bazzo-Romagnolli AP, Gimenez-Carvalho B, Polo de Almeida Nunes EF. Gestão de unidade básica de saúde em municípios de pequeno porte: instrumentos utilizados, facilidades e dificuldades relacionadas. Rev. Gerenc. Polit. Salud. 2014; 13(27): 168-180. http://dx.doi.org/10.11144/Javeriana.rgyps13-27.gubs 


\section{Resumo}

Objetivo: analisar o cotidiano do trabalho de gerentes e o uso de instrumentos para o gerenciamento de unidades básicas de saúde (UBS). Método: estudo qualitativo, de caráter compreensivo, cujos dados foram obtidos por meio de dois grupos focais com 12 gerentes de uBs de municípios de pequeno porte do Paraná - Brasil, realizados no mês de julho de 2011. Resultados: ressalta-se o caráter dialético das situações do cotidiano que interferem no trabalho gerencial, que ora facilitam ora dificultam o trabalho. Instrumentos mencionados na organização do trabalho: a epidemiologia para subsidiar o planejamento, pactuação de metas e avaliação das ações, e na gestão dos trabalhadores: reuniões com a equipe, supervisão e mediação de conflitos. Conclusão: o gerente pode se constituir como elemento fundamental para a implementação de mudanças tendo em vista sua destacada atuação, tanto na organização do trabalho como na gestão dos trabalhadores.

Palavras chave: administração de serviços de saúde; atenção primária à saúde; centros de saúde; gerência; saúde da família; políticas públicas de saúde

\section{Resumen}

Objetivo: analizar el trabajo diario de los gerentes y el uso de instrumentos de gestión de las unidades básicas de salud (UBS). Método: estudio cualitativo, de carácter comprensivo, cuyos datos fueron obtenidos de dos grupos focales con doce gerentes de uBS de municipios de pequeño porte de Paraná, Brasil, realizados en el mes de julio del 2011. Resultados: se resalta el carácter dialético de las situaciones del cotidiano que interfieren en el trabajo gerencial, que a veces facilitan o dificultan el trabajo. Instrumentos mencionados en la organización del trabajo: la epidemiología para subsidiar la planificación, la negociación de metas, la evaluación de las acciones y la gestión de los trabajadores; reuniones con el equipo, supervisión y mediación de conflictos. Conclusión: el gerente puede ser el elemento fundamental para la implementación de cambios, con el fin de una destacada gestión tanto en la organización del trabajo como en la gestión de los trabajadores.

Palabras clave: administración de los servicios de salud; atención primaria de salud; centros de salud; gerencia; salud de la familia; políticas públicas de salud

\section{Abstract}

Objective: To analyze the daily work of managers and the use of management instruments of basic health units (UBS). Method: A comprehensive-type qualitative study; the data for the study were obtained from two focus groups with twelve managers of UBS from small municipalities of Paraná, Brazil, performed in July, 2011. Results: The dialectic nature of the everyday situations that interfere with the management work needs to be highlighted. These situations sometimes make work easier or harder. Instruments mentioned in the organization of work: the epidemiology to subsidize planning; goal negotiation; assessment of actions and management of workers; team meetings; supervision and mediation of conflicts. Conclusion: The manager may be the key element for the implementation of changes aimed at a prominent management of work organization as well as management of workers.

Keywords: management of health services; primary health care; health care center; management; family health; health public policies 


\section{Introdução}

No processo de implementação do sus, o princípio da descentralização provocou profundas mudanças no âmbito da organização e gestão dos serviços de saúde, principalmente por ser atribuída aos municípios a transferência de decisões e ações antes centralizadas.

Na prática, municipalizar a saúde é aplicar o princípio de descentralização, é trazer para o governo municipal a capacidade de definir, junto aos usuários, as ações e atividades do setor. Ao se tornar gestor dos recursos públicos, o gestor municipal tem maior possibilidade de responder de forma mais ágil aos problemas locais, de diminuir as fraudes, e de distribuir os recursos de maneira mais equânime, de acordo com sua realidade (1).

Neste processo, os municípios ao assumirem a gestão do sus, estruturaram uma ampla rede de serviços de saúde no âmbito da atenção básica e introduziram novos atores neste campo de atuação, com destaque para os gerentes de unidades de saúde. A principal atuação da gerência se dá na organização do trabalho e na gestão de recursos humanos (2), não podendo ser uma atividade meramente funcional, voltada para as atividades burocráticas, de manipulação dos papéis e rotinização do trabalho pré-derminado (3). Pelo contrário, pressupõe maior autonomia e poder decisório dos atores nas ações e serviços produzidos, considerados imprescindíveis para um cuidar em saúde com qualidade e resolutivo.

Neste sentido o papel desempenhado por estes gerentes é fundamental para assegurar a implantação do modelo de atenção pretendido pelo Sistema Único de Saúde, justificando-se desta forma este estudo sobre a atuação gerencial em serviços de atenção básica. Objetiva-se analisar o cotidiano do trabalho de gerentes, as facilidades e dificul- dades deste processo, e o uso de instrumentos e estratégias para o gerenciamento de UBS. Seus resultados permitem a identificação de potencialidades, a compreensão das fragilidades e a proposição de mecanismos para melhor enfrentá-las, contribuindo assim para o desenvolvimento de tecnologias de gestão em saúde mais adequadas.

Neste estudo a perspectiva teórica adotada para a abordagem da gerência na atenção básica é a teoria do processo de trabalho em saúde. Cabe destacar que a gerência pode ser apreendida, simultaneamente, como instrumento do processo de trabalho em saúde (3) e como processo de trabalho gerencial específico (2), sendo esta segunda, a abordagem utilizada para subsidiar a análise dos resultados deste estudo.

O processo de trabalho específico da gerência é composto por um conjunto de atividades próprias e inter-relacionadas, para cumprir uma determinada finalidade - o estabelecimento e a manutenção de condições favoráveis à implementação de um dado modelo assistencial (2), com vistas à integralidade da atenção ao usuário, ou seja, a satisfação de suas necessidades de saúde. Atua sobre determinado objeto, a partir de determinados instrumentos. $\mathrm{O}$ objeto de intervenção da gerência é a própria organização do trabalho e os trabalhadores da unidade de saúde. Os instrumentos do trabalho gerencial se constituem em saberes, técnicas e tecnologias.

Podem ser citados como instrumentos do trabalho gerencial: o planejamento, o dimensionamento, o recrutamento e seleção de pessoas, a avaliação de desempenho e de serviço, a educação permanente em saúde, a supervisão, os materiais, equipamentos e a instalação física (2). Merece destaque os diversos saberes expressos nas diferentes abordagens da gestão e gerência em saú- 
de, especialmente o lugar ocupados pelas práticas de comunicação e de participação democrática (4), ambos fundamentais para que a gerência cumpra a finalidade de seu trabalho.

Desta forma, no processo de trabalho específico, cabe ao gerente reunir um conjunto de instrumentos - saberes específicos, técnicas de ação e materiais - utilizados no desempenho de suas funções e que lhes permite instituir condições para interagir e promover a articulação dos trabalhadores para a organização do processo de trabalho em saúde.

\section{Metodologia}

Trata-se de uma pesquisa com abordagem qualitativa, de caráter compreensivo, na qual os sujeitos foram gerentes de unidades básicas de saúde, atuantes em municípios de pequeno porte da 17a Regional de Saúde (Rs) do Paraná. Este estudo integra uma pesquisa maior, denominada "Gestão do Trabalho na Rede Básica de Saúde em Municípios de Pequeno Porte da Região Norte do Paraná”, aprovada e financiada pela Fundação Araucária, na chamada de Projetos 08/2009 - Programa de Pesquisa para o sus: Gestão Compartilhada em Saúde.

De acordo com o Plano Diretor em Municípios de Pequeno Porte (5), publicado pelo Ministério das Cidades, municípios de pequeno porte são aqueles que possuem população de até 20.000 habitantes e representam $73 \%$ dos municípios brasileiros. $\mathrm{Na}$ região estudada a representatividade destes municípios é de $83 \%$ (6).

Os dados foram obtidos por meio de dois grupos focais, nos quais participaram 12 gerentes de UBS, seis em cada grupo. Foram realizados no mês de julho de 2011, na cidade sede da $17^{\mathbf{a}}$ Rs. Para participarem dos grupos focais foram convidados 16 gerentes de UBs localizadas em municípios de pequeno porte, integrantes desta região de saúde. Para o convite foram utilizados os seguintes critérios: tempo de pelo menos um ano na gerencia da unidade; desenvolvimento de bom trabalho gerencial (na avaliação de técnicos da Regional de Saúde da Secretaria de Saúde do Estado do Paraná); e ter interesse em participar de discussão sobre o trabalho gerencial. Os gerentes que participaram foram informados sobre a pesquisa, e ao concordarem em participar, assinaram um termo de consentimento livre e esclarecido.

As discussões do grupo focal foram orientadas por um roteiro contendo questões relacionadas ao trabalho gerencial: Como acontece a gerência dos trabalhadores da unidade; o que o gerente faz no cotidiano do trabalho da coordenação; que estratégias/ instrumentos utiliza na condução do trabalho gerencial; como se dá o apoio para o desenvolvimento do trabalho; e como é a interação com os trabalhadores, quais as facilidades e dificuldades na execução do trabalho.

Os grupos focais foram conduzidos por dois integrantes do grupo de pesquisa, e as discussões foram gravadas e transcritas na íntegra. Os dados foram trabalhados e editados quanto às correções gramaticais, excluídos os vícios de linguagem, pausas, interferências e ruídos do ambiente para permitir ao leitor a compreensão do sentido da entrevista. Para evitar a identificação dos participantes, suas falas foram codificadas com as letras do alfabeto, na ordem em que surgiam: G1F1, G2F1[...]G1F2, [...], G6F2, representando cada um dos gerentes participantes e os grupos focais, respectivamente.

Para a análise do material empírico foi utilizada a técnica de análise temática de conteúdo que "consiste em descobrir os núcleos de sentido que compõem a comunicação e 
cuja presença, ou frequência de aparição pode significar alguma coisa para o objetivo analítico escolhido" (7).

A análise de conteúdo prevê a organização e realização das atividades em três etapas: a pré-análise; a exploração do material e o tratamento dos resultados, ou seja, a inferência e a interpretação (7). A pré-análise consiste numa fase de organização do material a ser analisado. Nesta fase foi realizada a leitura flutuante, de forma a possibilitar a impregnação de seu conteúdo. A exploração do material consistiu em operações de codificação/ categorização, processo pelo qual os dados brutos foram transformados e agregados em unidades. $\mathrm{O}$ tratamento dos resultados consistiu na interpretação da categorização realizada, e foi feita a partir dos objetivos do estudo (7).

Os aspectos éticos foram respeitados. A pesquisa foi submetida e aprovada pelo Comitê de Ética da instituição de atuação de um dos autores e foi aprovada sob parecer n⿳0 232/09, CAAE No 4255.0.000.268-09.

\section{Resultados}

A análise dos resultados possibilitou a construção de duas categorias empíricas: trabalho gerencial - facilidades e dificuldades manifestas e estratégias e instrumentos utilizados no trabalho gerencial.

\section{Trabalho gerencial - Facilidades e dificulda- des manifestas}

Os gerentes expressaram que a finalidade do seu trabalho é contribuir para organizar os serviços de saúde, proporcionando um atendimento mais humanizado ao usuário, para que o mesmo tenha suas necessidades

172 de saúde satisfeitas. Ressaltaram, porém, que os imprevistos fazem com que o gerente tenha que "intervir numa coisa e noutra," (G1, GF2) e isso faz com que o trabalho gerencial seja pouco efetivo. Apesar de terem clareza da finalidade de seu trabalho, ressaltam que sentem dificuldades no exercício cotidiano do gerenciamento.

Vários autores que estudam o trabalho gerencial (8) também apontam dificuldades nesta prática, em determinada realidade, diferentes contextos e momentos históricos, observa-se que os cenários se repetem, os problemas se assemelham. Estes autores relatam dificuldade em conciliar a administração da assistência e a prestação do cuidado direto ao cliente com a realização de tarefas para o gerenciamento do pessoal e do setor de trabalho, fato que gera sofrimento e frustração no exercício de suas funções (8).

Outros autores (9) apontam que nas unidades da Atenção Básica os enfermeiros desenvolvem, no dia a dia, múltiplas atividades no campo da assistência na estratégia Saúde da Família (ESF), da gerência e da educação, ampliando as responsabilidades, que associadas às dificuldades existentes e ao interesse em proporcionar o bom andamento do serviço, sobrecarregam o seu cotidiano, o que acarreta sentimento de sobrecarga, estresse e insatisfação com o trabalho (9).

Os entrevistados apontaram que uma facilidade para alcançar a finalidade de seu trabalho se refere ao conhecimento que o gerente possui de toda a unidade, pois como é o único profissional nesta função, acaba por ter uma visão mais ampla de tudo o que ocorre, facilitando a tomada de decisão, como exemplificado na fala abaixo:

\footnotetext{
Se você é só um, você sabe de tudo um pouco e isso facilita. Às vezes acontece algo, mas você está sabendo que isso que está acontecendo é devido a alguma coisa maior que está vindo lá de cima, então isso facilita (G2, GF1).
} 
No entanto, essa visão mais ampliada fica prejudicada em alguns municípios, segundo os entrevistados, por falha na comunicação interna com outros setores da administração municipal.

Apontaram como fragilidade para o exercício da função gerencial a não formalização legal do cargo de gerente e consequentemente o não recebimento de gratificação pelo exercício dessa função em muitos municípios. Relatam que são referência para a parte técnica, porém têm autonomia relativa para o gerenciamento dos trabalhadores, quanto à divisão de tarefas e de coordenação da unidade básica.

Já os gerentes que atuam em municípios cuja função é institucionalizada/formalizada referiram essa função como depositária de confiança do secretário de saúde, dos demais trabalhadores e de usuários. Segundo o depoimento de um gerente, a confiança se constitui tanto em ponto positivo, pelo fato de confiarem em sua liderança, como negativo, pela grande responsabilidade que recai sobre quem assume essa função, ocasionando sobrecarga no trabalho gerencial, como explicitado na fala a seguir:

Eu acredito que é uma facilidade que depositem confiança no meu trabalho e uma dificuldade também, porque você acaba tendo que abraçar muita coisa por essa confiança que a pessoa deposita em você. Até mesmo a questão de paciente, tem outra pessoa que pode fazer o mesmo serviço que você, mas ele vai em você (G5, GF1).

Nos pequenos municípios, a proximidade do secretário de saúde com a gerência da unidade foi apontado como fator facilitador para o trabalho, pois dessa forma possuem mais respaldo para o desenvolvimento de ações. Referiram também haver dificuldades nessa relação, pois algumas vezes os secretários de saúde são despreparados e muitos de seus interesses destoam da finalidade que os serviços de saúde deveriam atingir. Relatam sobre atitudes populistas dos gestores (secretários e prefeitos) na área da saúde com intuito de conseguirem retorno político. Reforçam a dificuldade de gerenciar quando os secretários municipais não são da área da saúde e não compreendem a complexidade desse setor.

$\mathrm{O}$ ano eleitoral e a troca de gestão foram observados como sendo problemas para gerência da unidade. Disseram que em cidades pequenas a saúde é muito usada como mote para campanhas eleitorais, havendo ingerência política para os atendimentos, agendamento de exames, atenção especializada, entre outros. Nesse período a organização do serviço fica prejudicada, pois tudo que possa causar algum impacto é visto como politicamente incorreto para o momento, e há ressalva para a implantação de qualquer mudança. A fala de uma das participantes do grupo focal é ilustrativa dessa dificuldade: “esta questão política é difícil, porque a hora que você fala um não para a população, você esta falando um não para o voto" (G4, GF1).

André e Ciampone (10) corroboram os resultados deste estudo ao apontar que um gestor despreparado para tal função é um dos problemas encontrados no serviço público, pois propicia discrepâncias quanto à liderança necessária para conduzir processos de mudança e executar políticas de saúde, levando à manutenção de projetos que devem ser superados. Analisam que na atenção básica a gerência enfrenta limitações de diversas ordens: financeiras, da legislação municipal e do exercício de subjetividades permeadas pelas relações de poder advindas da dimensão político-partidário. Ximenes Neto e Sampaio (11) também apontam que há conflitos ideológicos no gerenciamento da ESF, o que faz com que os gerentes se situem numa delicada posição administrativa, para desenvolver um processo de trabalho que seja adequado às necessidades de saúde $\mathrm{e}$ às diferentes realidades, numa estrutura mínima. 
Outro fator referido nesta pesquisa como facilitador para o desenvolvimento do trabalho é a colaboração existente entre os trabalhadores e entre estes e a gerência, o que possibilita o desenvolvimento de várias atividades atribuídas à ela, mas que seriam difíceis de serem realizadas exclusivamente pela gerência, devido ao excesso de atividades que recaem sobre a mesma. A relação de confiança e de colaboração existente entre profissionais de enfermagem, médicos das equipes do PSF, dentre outros - possibilita que estes assumam o desenvolvimento de determinadas funções, como o monitoramento e coordenação de algumas ações e programas. A esse respeito foi referido que:

Têm funcionários chave, na epidemiologia eu tenho uma auxiliar que ela é meu braço direito, esquerdo, tudo. E na atenção básica mesmo são as enfermeiras das equipes, conto muito com elas. (G2, GF1)

São pessoas que se destacam na equipe e que você delega [...] tenho uma auxiliar que assume a parte da saúde criança, tenho a enfermeira que assume o pré-natal. (G4, GF1)

No contexto contemporâneo das práticas de saúde em que se reconhece a complexidade dos problemas de saúde, torna-se necessário que o trabalho seja desenvolvido numa lógica de colaboração, ou seja, com a articulação das ações e interação entre os profissionais (12). O desenvolvimento do trabalho em equipe pressupõe a existência de vínculo e confiança entre profissionais, aspectos necessários para o trabalho coletivo.

\section{Estratégias e instrumentos utilizados no trabalho gerencial}

No exercício cotidiano do trabalho gerencial 174 foi discutida a utilização de estratégias e instrumentos tanto para a organização do trabalho - utilização de informações epidemiológicas para subsidiar o planejamento e avaliação de ações - como para a gestão dos trabalhadores: reunião de equipe, supervisão do trabalho e a mediação dos conflitos.

\section{Instrumentos para a Organização do}

Trabalho. Em relação aos instrumentos e estratégias gerenciais para a organização do trabalho, foi destacada a importância do setor da epidemiologia para subsidiar o planejamento e avaliação das ações de saúde. Relatam que o trabalho conjunto entre o setor da epidemiologia e a unidade de saúde é um fator positivo para caracterização da área em que atuam, pois propicia o reconhecimento da situação, dos problemas de saúde existentes no território de abrangência das unidades de saúde. No entanto, referem que os agravos identificados e/ou notificados e os indicadores de saúde deste território deveriam ser discutidos com a equipe da unidade, e isso nem sempre acontece.

Foi apontado que a epidemiologia possibilita a alimentação dos sistemas de informação - e citaram como exemplos: o Sistema Nacional de Nascidos Vivos (SINASC), Sistema Nacional de Agravos de Notificação (sinAN), Sistema de Informações sobre Mortalidade (SIM), dentre outros, e que esse procedimento é essencial para que o município receba regularmente as transferências intergovernamentais de recursos. No entanto os participantes referiram que os gestores nem sempre valorizam esse setor e/ou fazem os investimentos que seriam necessários para ampliar sua funcionalidade, como explicitado na fala de um gerente:

[...] o que acontece numa equipe de saúde pública é que a maioria desconhece que a epidemiologia gera recurso financeiro pra secretaria de saúde [...]. Para meu gestor entender isso demorou, falei pra ele se a epidemiologia tá funcionando você tá rece- 
bendo dinheiro, se a epidemiologia deixar de funcionar você vai deixar de receber recursos. (G1, GF2)

Como ponto positivo na utilização da epidemiologia, os gerentes manifestaram que as metas pactuadas anualmente pelo sistema de pactuação de indicadores de saúde (SISPACTO), exercem influência no que é determinado como prioridade para ser desenvolvido pela unidade de saúde. Houve ainda um comentário de que para alguns gerentes os relatórios mensais auxiliam na identificação do que está dando certo ou errado em relação ao cumprimento das metas pactuadas e o que ainda há necessidade de ser implementado em relação às ações de saúde. Desta forma, os relatórios mensais de produção se instituem como um instrumento de monitoramento do que foi pactuado.

Aqueles que utilizam o SISPACTO relataram realizar uma avaliação parcial, em relação ao cumprimento das metas pactuadas, já na metade do ano. Utilizam essa estratégia para que dê tempo de instituir medidas para aquelas ações e serviços que estejam abaixo das metas esperadas para o período, e para que as mesmas possam ser alcançadas ao final de 12 meses. As estratégias utilizadas para aumentar a cobertura das ações e serviços que estejam abaixo do pactuado foram: busca ativa de faltosos às atividades agendadas e campanhas (de coleta de citologia oncótica e de vacinas) no decorrer do ano.

Alguns gerentes demonstraram a existência de tensão no trabalho gerencial entre o cumprimento das metas pactuadas e a pressão para o atendimento à demanda e aos agravos inesperados, como foi o caso da epidemia de dengue. Relatam que estes fatos geram dificuldade no cumprimento das metas para a maioria dos municípios, e citam como exemplo que "no ano passado nós deixamos de fazer muita coisa por causa da epidemia de dengue, nós deixamos de colher preventivo porque não tinha profissional suficiente para tocar a demanda" (G1, GF2).

Citaram que o SISPACTO deveria servir para orientar a programação e o planejamento das ações a serem desenvolvidas em cada unidade, mas enfatizam a dificuldade de se organizarem frente às demandas que surgem no dia a dia. Referem que "vivem apagando incêndios" (G2, GF2). Ou seja, apontam como dificuldade a definição e estabelecimento das prioridades para o trabalho, pois referiram que normalmente acabam priorizando a demanda do momento - os atendimentos de urgência e emergência. Desta forma, "não estamos conseguindo estabelecer realmente quais são as prioridades. E aí você apaga o fogo daquele momento [...]" (G4, GF1).

Percebeu-se divergência no entendimento dos gerentes quanto à participação da Regional de Saúde em relação às pactuações realizadas. Para um grupo, a Regional de Saúde cumpre papel relevante no monitoramento e avaliação do que foi pactuado, uma vez que toma a iniciativa de chamar os municípios para avaliação do que foi atingido no ano anterior, previamente à pactuação de novas metas. Manifestaram que a relação com a regional de saúde é vista como apoio, e que apesar de realizarem cobranças para o desenvolvimento de ações pactuadas, prestam auxílio quando surgem dúvidas no serviço.

\footnotetext{
Eu vejo assim a regional, lógico que a função deles de uma certa maneira é cobrar, mas também eu sinto um apoio porque faz oito anos que estou trabalhando, mas qualquer dúvida que eu tenho, pego o telefone e ligo. (G4, GF1)
}

Para o outro grupo há incoerência das pactuações realizadas para os pequenos municípios, dando a entender que não é 
considerada, pelos técnicos da Regional de Saúde, a realidade local, especialmente o reduzido número de profissionais no serviço para estarem cumprindo essas pactuações. Esse comentário dá a conotação de que as metas não são pactuadas e sim impostas para estes municípios, como aponta a fala abaixo:

[...] a pactuação é incoerente. O meu município tem uma realidade e [nome de um município de grande porte] totalmente outra, meu município é 10 mil habitantes. O Estado determina que mesmo que eu não atingir ou possivelmente possa atingir eu vou manter aquela pactuação porque o Estado determina que eu tenho que pactuar, isso é para todos. Então acho isso incoerente. (G1, GF2)

Como dificuldades para o planejamento e avaliação das ações foram referidos: a infra-estrutura deficitária, como a falta de computador para o fechamento de relatórios; a centralização do Sistema de Informação da Atenção Básica (SIAB), o que dificulta o acesso às informações desse sistema; e os imprevistos que ocorrem no cotidiano do trabalho, como as urgências que chegam às unidades, as epidemias e surtos, que consomem todo o tempo que seria destinado ao planejamento e avaliação das ações.

Cubas (13) aponta que o planejamento é a habilidade de maior importância para o gerenciamento e que no cotidiano do trabalho dos gerentes existem dificuldades para realizá-lo, mas considera que o planejamento acontece e está embutido nos processos gerenciais, e que a avaliação é tão importante quanto o planejamento. Rivera e Artmann (14) reforçam esta idéia, de que o planejamento está situado no interior do processo de gerenciamento de um serviço/ sistema de saúde, sendo uma ferramenta 176 organizacional, integrante do processo de desenvolvimento das organizações. Enten- dem que as possibilidades do planejamento são mediadas e subordinadas à cultura das organizações.

Em relação ao o monitoramento de indicadores de saúde e à pactuação realizada, Pinheiro(15) e Fernandes, Machado e Anschau (16) analisam que para realizá-los implica que o gerente saiba lidar com tecnologias duras, ou seja, saiba utilizar os sistemas de informação, manipular e analisar bancos dados, e isso nem sempre acontece.

Superada esta situação, é necessário que as informações estejam atualizadas, localizáveis e acessíveis. Porém, muitas vezes ocorre que quem opera os bancos de dados epidemiológicos mantém as informações centralizadas, ou seja, não as devolve para a unidade de saúde, o que também pode ser um obstáculo para a pactuação, monitoramento e avaliação mais sistematizada das ações e serviços de saúde (17).

\section{Instrumentos para a Gestão dos Trabalhado-} res. Para a gestão dos trabalhadores a principal atividade referida pelos participantes foi a reunião com a equipe da unidade, em que "a gente reúne a equipe, os profissionais sentam e vamos discutir e ver o que a gente pode estar fazendo para ajudar" (G2, GF2).

Para a realização dessas reuniões foram relatadas estratégias diversas: alguns disseram não fechar a unidade, mas que realizam reuniões por equipe ou categoria profissional durante o expediente; outros afirmaram reunir a equipe uma hora por semana ou mês, em dia e horário previamente estipulados.

Referiram haver dificuldades para que a reunião seja instituída como uma atividade do cotidiano do trabalho e com a participação de todos os trabalhadores. Alguns reúnem a equipe esporadicamente, só para resolver o problema do momento e neste caso a co- 
municação com a equipe acontece apenas informalmente, com alguns membros e em horários alternativos, sobre as dificuldades diárias e não sobre metas e/ou planejamento do serviço, tendo desta forma um caráter mais instrumental, como pode ser visto no excerto a seguir:

\section{[...] não existe assim: vamos sentar e nos reunir pra discutir alguma coisa; é reunião pra apagar incêndio. De vez em quando tem uma reunião, uma vez por mês pra estar colocando alguma coisa no lugar, se tem alguma coisa errada [...] é mais pra isso. Mas pra você planejar, discutir alguma coisa que você quer, não existe. (G6, GF2)}

Apesar de nem todos conseguirem realizar reunião com a equipe, houve depoimentos daqueles que conseguem, e nas reuniões, além de discutir estratégias, problemas ou demandas, realizam atividades educativas junto à equipe de trabalhadores, como aponta uma das entrevistadas: "Através de reuniões eu faço educação continuada com eles. No começo todo mundo reclama, todo profissional reclama, mas depois vai aceitando" (G6 GF1).

Dificuldades semelhantes foram apontadas por Peduzzi (18) e estão relacionadas à questão estrutural - pelos diferentes turnos de trabalho e ausência de espaço físico adequado; às interações - tal como a pouca disponibilidade de tempo dos profissionais, em especial dos médicos; e distorções da comunicação.

A não garantia de espaços de discussão dos trabalhos colabora para que o planejamento dos atos de saúde ocorra de forma individualizada, com cada trabalhador definindo e programando suas atividades, fazendo com que a equipe perca seu potencial de articulação entre os campos disciplinares.
Para que a equipe possa se analisar na produção de seu trabalho e desenvolver um trabalho coletivo, considerando as características do trabalho em saúde, ela necessita de espaço e tempo (19); necessita de espaços compartilhados, em que os trabalhadores integrantes possam se reunir, conversar e elaborar planos de atendimento conjunto para cada família (20). Apesar da importância das reuniões para as equipes, os autores alertam para o fato de que as modificações necessárias não se darão apenas com a existência desse espaço, mas, sobretudo da forma como ele é utilizado (20).

Em relação à gestão dos trabalhadores, merece ser destacado que nos pequenos municípios nem sempre existe e está estruturada a área de gestão dos recursos humanos. Desta forma, cabe à gerência da unidade de saúde o desenvolvimento de atividades relacionadas à gestão do trabalho na unidade, principalmente a supervisão, a alocação e o remanejamento de trabalhadores, bem como a mediação dos conflitos.

Como dificuldades para a gestão dos trabalhadores foram relatadas situações de ingerência política em que, em algumas situações, quem libera o funcionário para as férias é o secretário de saúde e não a gerência da unidade, ocasionando desfalque em alguns setores. Essa dificuldade acaba por fazer com que o gerente da unidade, que na maioria dos municípios exerce a gerência informalmente, não assuma determinadas posições e atitudes que desagradam os trabalhadores, tendo em vista que não se sentem respaldados para tais enfrentamentos, como apontado no trecho abaixo:

Não é que eu não quero me indispor com o funcionário, mas eu não tenho uma formalidade pra me indispor com o funcionário, então eu não vou ter um respaldo, porque eu sou enfermeira como os outros três que estão na unidade que é de PSF. (G1, GF2) 
No entanto, essa manifestação não foi unânime entre todos os participantes, havendo também depoimentos que revelam certo grau de autonomia para o remanejamento e alocação dos trabalhadores, quando há problemas de adaptação em um local ou em determinada função.

A ingerência política foi discutida enfaticamente entre os entrevistados, com destaque para o que ocorre em ano eleitoral, no qual a autonomia do gerente se torna ainda mais relativa. Nos municípios menores tanto a população como os trabalhadores possuem maior acesso aos gestores e buscam, por meio desse contato, o atendimento de seus interesses.

Estudo feito por Fernandes, Machado, Anschau (21) referenda estes resultados, retratando dificuldades enfrentadas pelos gerentes devido às decisões centralizadas, à política partidária, à mudança de governo, à demora das respostas pela secretaria municipal de saúde.

Também foi discutida a ocorrência de situações conflituosas decorrentes da interação entre trabalhadores e entre estes e os usuários, cabendo ao gerente da unidade a mediação das mesmas. Foram relatadas distintas estratégias para a mediação dos conflitos envolvendo dois ou mais trabalhadores da equipe: alguns chamam os envolvidos para conversar juntos, como numa acareação; outros preferem ouvir a versão de cada um em particular para depois tomar uma atitude. Ambos referiram apresentar bons resultados.

Como causa freqüente de conflitos na equipe, foi apontado o descomprometimento de alguns funcionários com o trabalho coletivo, e que este tipo de situação provoca dificuldades para a gerência, principalmente quando este é concursado ou possui indicação política. Referiram que muitos destes funcionários não cumprem com suas atribuições e vão apenas para receber o salário no final do mês. Também foram mencionadas outras causas de conflitos entre os trabalhadores: o não cumprimento de horário por profissionais de algumas categorias, principalmente médicos e dentistas; insatisfação de alguns agentes comunitários de saúde mais qualificados (alguns até pós-graduados) com suas atribuições, e por isso não querem sair para realizar visitas domiciliares, ficam na UBS realizando atividades que não integram suas funções; falta de interação de algumas equipes de odontologia com a os demais trabalhadores da unidade e a não utilização de protocolos por alguns profissionais.

Quanto aos conflitos envolvendo usuários do serviço, a maioria das vezes foi devido ao não atendimento às necessidades trazidas para a unidade, sendo mais comum a falta de vagas para consultas médicas ou problemas que não são da governabilidade dos trabalhadores e gerentes da unidade. Mesmo sendo explicadas as normas e limites do serviço são frequentes as manifestações de conflitos entre os usuários e os trabalhadores, já que estes são "a linha de frente". Completam ainda que quando a ESF não atende as necessidades desejadas para aquele momento, a população recorre ao prefeito, secretário de saúde ou à própria gerência, na busca de solucionar seus problemas.

São poucos os estudos realizados que analisam as causas do conflito na atenção básica. Entre os estudos identificados (22-25), as principais causas dos conflitos interpessoais no trabalho em saúde apontadas foram: o descompromisso de membros da equipe e a falta de colaboração para com o trabalho coletivo, bem como a dificuldade de comunicação e as diferentes personalidades e valores dos integrantes da equipe de trabalho. Carvalho (22) aponta que a infraestrutura e organização deficitária da rede de serviços 
do SUS são causas freqüentes de conflitos envolvendo usuários e trabalhadores dos serviços de saúde da atenção básica.

Outros estudos que analisaram a atuação gerencial frente a situações conflituosas também apontam que nestas situações é o gerente a referência para a equipe e é ele quem faz a mediação entre os envolvidos no conflito (22,26-28).

\section{Considerações Finais}

A partir dos resultados apresentados neste estudo conclui-se que o gerente pode se constituir em um elemento fundamental para a implementação de mudanças nos serviços de saúde em pequenos municípios, com vistas à integralidade da atenção aos usuários no Sistema Único de Saúde (sus), tendo em vista sua destacada atuação tanto na organização do processo de trabalho como na gestão dos trabalhadores.

Varias situações vivenciadas no cotidiano do trabalho nos pequenos municípios interferem no trabalho gerencial, podendo ser citadas: o acúmulo de atividades (gerenciais e assistenciais); a visão ampliada da realidade (dos recursos existentes e das pessoas), a falta de reconhecimento institucional da função gerencial, a proximidade com o secretário de saúde e a ingerência política, o que corrobora os achados de outros estudos sobre a atuação gerencial em unidades básica de saúde. Ressalta-se o caráter dialético destas situações, tendo em vista que uma mesma situação ora facilita ora dificulta o trabalho gerencial, dependendo da situação e dos envolvidos nela, ou seja, do contexto em que se manifesta.

No desempenho do trabalho gerencial foram citadas como estratégias e instrumentos para a organização do trabalho: o uso da epide- miologia para subsidiar o planejamento, a pactuação de metas e a avaliação das ações desenvolvidas; e na gestão dos trabalhadores: as reuniões com a equipe; a supervisão dos trabalhadores e a mediação de conflitos. A forma como estas estratégias e instrumentos são utilizados e os resultados que as mesmas podem produzir são influenciados por vários fatores: a infra estrutura dos serviços, o preparo do gestor, a política partidária, o compromisso dos profissionais da equipe para com os objetivos do trabalho conjunto, o apoio da Regional de Saúde e principalmente do preparo do gerente.

Reconhece-se que o contexto influencia fortemente o desempenho gerencial, mas ele é ao mesmo tempo influenciado pela atuação do gerente. Neste sentido, para potencializar sua atuação é necessário que estes gerentes se atentem para a necessidade de qualificar sua atuação junto aos trabalhadores, destinando, às atividades com os demais trabalhadores da unidade, espaço e tempo, suporte e manejo. Para que tenha essa atuação o gerente deve se reconhecer com tal e deve se qualificar para que possa compreender, suportar e interagir com os dramas vivenciados no cotidiano do trabalho, reconhecendo-se como integrante da equipe de trabalho, porém não como mais um ou qualquer um, mas como aquele que desempenha uma função diferenciada (29).

\section{Referências}

1. Gil CR, Martin G, Gutierrez PR. A Organização dos serviços em Londrina e região. In: Andrade SM, Soares DA, Cordoni Junior L, organizadores. Bases da Saúde Coletiva. Londrina: Ed. UEL; 2001. p. 61-92.

2. Felli VEAF, Peduzzi M. O trabalho gerencial em enfermagem. In: Kurcgant P, coordernador. Gerenciamento em enfermagem. São Paulo: Guanabara Koogan; 2005. p. 1-13.

3. Mishima SM, Villa TCS, Silva EM, Gomes ELR, Anselmi ML, Pinto IC, et al. Organização do processo gerencial no trabalho em saúde pública. In: Almeida MCP, Rocha SM, organizadores. O trabalho de enfermagem. São Paulo: Cortez; 1997. p. 251-96. 
4. Peduzzi M. Trabalho em equipe de saúde da perspectiva de gerentes de serviços de saúde: possibilidades da prática comunicativa orientada pelas necessidades de saúde dos usuários e da população [tese de livre docência]. São Paulo: Escola de Enfermagem, Universidade de São Paulo; 2007.

5. Ministério das Cidades (Brasil), Secretaria Nacional de Problemas Urbanos. Plano Diretor em Municípios de pequeno porte [Internet]. [acesso em 2011 set. 28]. Disponível em: http://portal.cnm. org.br/sites/8800/8875/download/2_dia/PlanoDiretoremMunicipiosdepequenoporte_Modificada.pdf.

6. Nunes EFPA. Gestão do processo de trabalho na rede de atenção básica de saúde em municípios de pequeno porte da região norte do Paraná. Projeto de pesquisa cadastrado na Universidade Estadual de Londrina sob no 6919. Londrina: UEL; 2010.

7. Bardin L. Análise de conteúdo. Lisboa: Edições 70; 2009.

8. Jorge MSB, Freitas CHA, Nóbrega MFB, Queiroz MVO. Gerenciamento em Enfermagem: um olhar crítico sobre o conhecimento produzido em periódicos brasileiros (2000-2004). Rev Bras Enferm. 2007 jan/fev; 60 (1): 81-6.

9. Villas Boas LMFM, Araujo MBS, Timóteo RPS. A prática gerencial do enfermeiro no PSF na perspectiva da sua ação pedagógica educativa: uma breve reflexão. Ciênc. Saúde Coletiva. 2008 jul/ag; 13 (4): 1355-60.

10. André AM, Ciampone MHT. Competências para a gestão de Unidades Básicas de Saúde: percepção do gestor. Rev Esc Enferm USP. 2007; 41 (esp): 835-40.

11. Ximenes Neto FRG, Sampaio JJC. Análise do processo de trabalho dos gerentes no território da Estratégia Saúde da Família. Rev Gerenc Polit Salud. 2012 enero/jun;11 (22): 76-91.

12. André AM, Ciampone MHT. Competências para a gestão de Unidades Básicas de Saúde: percepção do gestor. São Paulo: Rev Esc Enferm USP. 2007; 41(esp): 835-40.

13. Peduzzi M, Sangaleti CT, Aguiar C, Souza GC, Silva JAM. Trabalho em equipe sob a perspectiva interprofissional. In: Vale EG, organizadora geral. Proenf Gestão. Porto Alegre: Artmed/Panamericana Editora, 2012; 1 (3). p. 9-39.

14. Cubas MR. Planejamento local: a fala do gerente de unidade básica de saúde. Rev Bras Enferm. 2005; 58 (03): 278-83.

15. Rivera FJU, Artmann E. Planejamento e gestão em saúde: flexibilidade metodológica e agir comunicativo. In: Rivera FJU. Análise estratégica em saúde e gestão pela escuta. Rio de Janeiro: Fiocruz; 2003. p. 17-35.

16. Pinheiro ALS. Gerência de enfermagem em unidades básica: a informação como instrumento para a tomada de decisão. Rev APS. 2009; 12 (03): 262-70.
17. Fernandes LCL, Machado RZ, Anschau GO. Gerência de serviços de saúde: competências desenvolvidas e dificuldades encontradas na atenção básica. Ciênc Saúde Coletiva. 2009 set/out;14 (supl. 1): s1541-52.

18. Pereira SA. Modos de gerenciar cuidado e serviço no programa saúde da família em Belo Horizonte [dissertação]. Belo Horizonte: Escola de Enfermagem, Universidade de Minas Gerais; 2005.

19. Peduzzi M, Carvalho BG, Mandu ENT, Souza GC, Silva JAM. Trabalho em equipe na perspectiva da gerência de serviços de saúde: instrumentos para a construção da prática interprofissional. Physis. 2011; 2 (2): 629-46.

20. Matumoto S, Fortuna CM, Mishima SM Pereira MJB, Domingos MAN. Supervisão de equipes no Programa de Saúde da Família: reflexões acerca do desafio da produção de cuidados. Interface Comun Saúde Educ. 2005; 9 (16): 9-24.

21. Fortuna CM, Mishima SM, Matumoto S, Pereira MJB. Team work in a family health care program: the team process concept and operational teams. Rev Lat Am Enferm. 2005; 13 (2): 262-8.

22. Fernandes LCL, Machado RZ, Anschau GO. Gerência de serviços de saúde: competências desenvolvidas e dificuldades encontradas na atenção básica. Ciênc Saúde Coletiva. 2009; 14 (1): 1541-52.

23. Carvalho, BG. Coordenação de unidade da atenção básica no SUS: trabalho, interação e conflitos [tese]. São Paulo: Escola de Enfermagem de São Paulo, Universidade de São Paulo; 2012.

24. Brown J, Lewis L, Ellis K, Stewart M, Freeman TR, Kasperski JM. Conflict on interprofessional primary health care teams - can it be resolved? J Interprof Care. 2011 Jan; 25: 4-10.

25. Corradi EM, Zgoda LTRW, Paul MFB. O gerenciamento de conflitos entre a equipe de enfermagem. Cogitare Enferm. 2008 abr/jun; 13 (2): 184-93.

26. Long S. Primary health care team workshop: team memhers' perspectives. J Adv Nurs. 1996 May; 23 (5): 935-41.

27. Guerra ST, Prochnow AG, Fontoura CMH, Santos JLG. El conflicto en la gerencia de enfermería: un análisis de la producción científica brasileña. Index Enferm [Internet]. $2010 \mathrm{Feb}$ [acesso em 2014 mar 25]; 19(2-3): 147-51. Disponível em: http://scielo.isciii.es/scielo.php?pid=S1132$12962010000200017 \&$ script $=$ sci arttext

28. Prochnow AG, Leite JL, Erdmānn AL, Trevizan MA. O conflito como realidade e desafio cultural no exercício da gerência do enfermeiro. Rev Esc Enferm USP. 2007; 41 (4): 542-50.

29. Onocko Campos, R. A gestão como espaço de intervenção, análise e especificidades técnicas. In: Campos GWS, Org. Saúde Paidéia. São Paulo: Hucitec, 2003, p. 122-49. 